Article

\title{
Heavy Oil Upgrading and Enhanced Recovery in a Steam Injection Process Assisted by NiO- and PdO-Functionalized $\mathrm{SiO}_{2}$ Nanoparticulated Catalysts
}

\author{
Luisana Cardona ${ }^{1}$, Daniela Arias-Madrid ${ }^{2}$, Farid B. Cortés ${ }^{2, *}$, Sergio H. Lopera ${ }^{1}$ and \\ Camilo A. Franco ${ }^{2, *}$ \\ 1 Grupo de Yacimientos de Hidrocarburos, Departamento de Procesos y Energía, Facultad de Minas, \\ Universidad Nacional de Colombia, 050034 Medellín, Colombia; lcardonar@unal.edu.co (L.C.); \\ shlopera@unal.edu.co (S.H.L.) \\ 2 Grupo de Investigación en Fenómenos de Superficie-Michael Polanyi, Departamento de Procesos y Energía, \\ Facultad de Minas, Universidad Nacional de Colombia, 050034 Medellín, Colombia; daariasma@unal.edu.co \\ * Correspondence: fbcortes@unal.edu.co (F.B.C.); caafrancoar@unal.edu.co (C.A.F.); \\ Tel.: +57-4-4255137 (F.B.C.); +57-4-4254313 (C.A.F.)
}

Received: 27 February 2018; Accepted: 22 March 2018; Published: 29 March 2018

\begin{abstract}
This work aims to investigate the effect of active catalytic nanoparticles on the improvement of the efficiency in recovery of a continuous steam injection process. Catalytic nanoparticles were selected through batch-adsorption experiments and the subsequent evaluation of the temperature for catalytic steam gasification in a thermogravimetric analyzer. A nanoparticulated $\mathrm{SiO}_{2}$ support was functionalized with $1.0 \mathrm{wt} \%$ of $\mathrm{NiO}$ and $\mathrm{PdO}$ nanocrystals, respectively, to improve the catalytic activity of the nanoparticles. Oil recovery was evaluated using a sand pack in steam injection scenarios in the absence and presence of a $500 \mathrm{mg} / \mathrm{L} \mathrm{SiNi1Pd1}$ nanoparticles-based nanofluid. The displacement test was carried out by constructing the base curves with water injection followed by steam injection in the absence and presence of the prepared treatment. The oil recovery increased $56 \%$ after steam injection with nanoparticles in comparison with the steam injection in the absence of the catalysts. The API gravity increases from $7.2^{\circ}$ to $12.1^{\circ}$. Changes in the asphaltenes fraction corroborated the catalytic effect of the nanoparticles by reducing the asphaltenes content and the $620{ }^{\circ} \mathrm{C}+$ residue $40 \%$ and $47 \%$, respectively. Also, rheological measurements showed that the viscosity decreased by up to $85 \%$ (one order of magnitude) after the nanofluid treatment during the steam injection process.
\end{abstract}

Keywords: enhanced oil recovery; extra-heavy oil; nanofluid; nanoparticle; steam injection; oil upgrading

\section{Introduction}

The growing demand for fossil fuels has led to an interest in exploiting unconventional reservoirs of heavy $(\mathrm{HO})$ and extra heavy crude oils (EHO), which are approximately of the same order as those of light and medium crude oils [1,2]. It is expected that for the 2014-2035 period, the development of $\mathrm{HO}$ and $\mathrm{EHO}$ oil resources would need approximately $9 \%$ of the cumulative investment upstream [3]. However, the production of heavy and extra-heavy oil is adverse due to the rheological properties that the crude oil has as a consequence of its high content of heavy compounds. In addition, the upgrading of $\mathrm{HO}$ and $\mathrm{EHO}$ requires large amounts of energy, leading to non-cost-effective processes at both surface and reservoir conditions.

Accordingly, several in-situ techniques have been employed for enhancing $\mathrm{HO}$ and EHO recovery with the objective of upgrading the oil and improving its viscosity and mobility. These techniques include thermal processes, such as steam assisted gravity drainage (SAGD) [4,5], cyclic steam 
stimulation (CSS) [6-9], steam flooding (SF) [10,11], in-situ combustion (ISC) $[12,13]$ and cold techniques using diluents, among others. The latter (i.e., cold processes) are employed for improving the crude oil mobility by dilution or destabilization of large amount of crude oil components in the reservoir by injecting solvents for viscosity reduction $[14,15]$. On the other hand, the thermal enhanced oil recovery techniques for heavy oil upgrading include aquathermolysis [16-18], pyrolysis—also called thermal cracking or thermolysis [19-22]—combustion processes [23,24] and low-temperature oxidation $[25,26]$. Nevertheless, most of these techniques do not exceed the $50 \%$ of oil recovery [27-29]. Hence, nanotechnology in the form of nanoparticles and nanofluids has obtained special attention to enhance the techniques above and increase oil recovery [30]. Further, nanoparticles with high catalytic activity towards heavy molecules decomposition may be employed for $\mathrm{HO}$ and $\mathrm{EHO}$ in-situ upgrading, increasing the oil recovery and quality as a cost-effective technology and reducing negative environmental impact [31-33]. In this sense, different materials have been employed for catalytic decomposition for the heavy fraction of heavy oil, including metallic, multimetallic and metal oxide nanoparticles [22,32,34,35], as well as supported hygroscopic salts (SHS) [36-38]. SHS materials consist of metal oxide nanoparticles over nanoparticulated support. Specially, bimetallic $\mathrm{NiO}$ and $\mathrm{PdO}$ nanoparticles over different supports of $\mathrm{Al}_{2} \mathrm{O}_{3}[39,40], \mathrm{TiO}_{2}[39]$ and $\mathrm{SiO}_{2}[37,38,41]$ nanoparticles have shown special capacity of simultaneously adsorbing and catalytic decomposing crude oil heavy fraction at relatively low temperatures $\left(\sim 220^{\circ} \mathrm{C}\right)$ due to the synergistic effect between the support and the active phase [36], generating availability for the technology application under real steam injection scenarios. Nevertheless, for field applications, the assessment of nanoparticles and nanofluids under dynamic tests and reservoir conditions is essential for the scale-up and thus guarantee the success of this type of technology. In this sense, few works have included nanocatalysts evaluation under dynamic conditions for evaluating the feasibility of nanoparticles injection in thermal EOR processes.

Farooqui et al. [42] performed CSS experiments in a heavy oil-containing silica sand pack using Ni nanoparticles at approximately $240{ }^{\circ} \mathrm{C}$. Ni nanoparticles were introduced to the porous media during the sand pack preparation. The authors found that the employed nanoparticles increased the oil recovery up to $10 \%$ during the CSS experiments in comparison with the system in the absence of nanoparticles. Yi, Babadagli and Li [43] studied the effect of Ni nanoparticles to promote aquathermolysis reactions under CSS experiments between 150 and $220{ }^{\circ} \mathrm{C}$. Nanoparticles were pre-mixed with the heavy oil for the experiments. The authors observed that higher oil recovery was obtained at $220{ }^{\circ} \mathrm{C}$ with a nanoparticle concentration of $0.20 \mathrm{wt} \%$ and was attributed to the level of aquathermolysis reactions occurring at this temperature. It was observed that nanoparticles act as catalysts by increasing the saturates fraction in comparison with the system in the absence of nanoparticles. Also, the authors concluded that the nanoparticles penetration into the sand pack plays a key role in the oil recovery. Hashemi et al. [31] employed in-situ prepared ultra-dispersed multi-metallic nano-catalysts of NiWMo within a vacuum gas oil matrix for the upgrading of Athabasca bitumen and enhanced recovery under conditions of pressure and temperature of a SAGD process $\left(320\right.$ to $340{ }^{\circ} \mathrm{C}$ ). The authors reported that the employed nanoparticles can enhance the bitumen recovery and upgrading by hydrogenation reactions that lead to viscosity reduction and increase of the API gravity. Also, the sulfur and nitrogen content, as well as the microcarbon residue, were reduced. Hamedi et al. [33] compared the effect an industrial micro-sized Raney nickel catalyst against Ni nanoparticles during steam-injection at $300^{\circ} \mathrm{C}$ for $\mathrm{HO}$ upgrading. Tests were performed in the absence and presence of a porous media. The results showed that the catalytic activity of nickel nanoparticles (in a mass base) was higher than that for Raney nickel catalyst. Further, the authors report that the catalytic process is improved in the presence of the porous media as the sand matrix behave as support for the Ni nanoparticles. In addition, the authors found that the particle distribution and reactivity are greatly influenced by the injection rate and direction, as well as the viscosity of the nanofluid. Azfal et al. [44] studied the effect of $\mathrm{Fe}_{2} \mathrm{O}_{3}$ nanoparticles in the oil recovery and quality of oil during steam injection at $295^{\circ} \mathrm{C}$. The authors reported that the oil recovery increased up to $30 \%$ in the presence 
of nanoparticles and that the oil viscosity was reduced up to $50 \%$, mainly attributed to the cracking of $\mathrm{C}-\mathrm{S}, \mathrm{C}=\mathrm{C}$ and $\mathrm{C} \equiv \mathrm{C}$ bonds in the heavy fraction of the crude oil.

However, until now there are no studies reporting the evaluation of SHS catalysts in steam flooding processes. Hence, this work aims to investigate the effect of active catalytic nanoparticles of silica functionalized with $\mathrm{NiO}$ and $\mathrm{PdO}$ nanoparticles in the improvement of the oil quality and the efficiency in recovery a continuous steam injection process. Oil recovery was evaluated using a non-confined sand pack in steam injection scenarios in the absence and presence of a water-based SHS-containing nanofluid. Changes in the physicochemical properties of crude oil were assessed using SARA analyses, simulated distillation (SimDis) measurements, changes in API gravity and rheological behavior.

\section{Results}

\subsection{Nanoparticles Characterization}

$\mathrm{SiO}_{2}$ nanoparticles functionalized with $1.0 \mathrm{wt} \%$ of nickel and palladium oxides (SiNi1Pd1) were used as a catalyst in the steam flooding process. $\mathrm{SiO}_{2}$ nanoparticles mean crystallite size was estimated at $7 \mathrm{~nm}$ with an $S_{\text {BET }}$ of $389 \mathrm{mg} / \mathrm{m}^{2}$. Also, the $S_{\text {BET }}$ of SiNi1Pd1 nanoparticles was $202 \mathrm{mg} / \mathrm{m}^{2}$ with $\mathrm{NiO}$ and $\mathrm{PdO}$ mean crystallite size of 1.3 and $2.2 \mathrm{~nm}$, respectively [36]. The mean aggregate size of the bimetallic nanoparticles in the aqueous solution was $61 \mathrm{~nm}$, as measured by dynamic light scattering (DLS) [36]. Additionally, the metal dispersion over the $\mathrm{SiO}_{2}$ nanoparticles was estimated in $18.3 \%$.

\subsection{Selection of Nanocatalyst}

The adsorption of asphaltenes onto nanoparticles is influenced by different factors including the heterogeneity of adsorbent surface, surface chemistry, nanoparticle size, asphaltenes chemical structure, the content of heteroatoms, among others [7]. Previous studies [36] have demonstrated that the asphaltene adsorption was higher for SiNi1Pd1 nanoparticles than for $\mathrm{SiO}_{2}$ support or monometallic SHS. SiNi1Pd1 nanoparticles are able to absorb up to $0.65 \mathrm{mg} / \mathrm{m}^{2}$ of asphaltenes, while $\mathrm{SiO}_{2}$ nanoparticles adsorb $0.14 \mathrm{mg} / \mathrm{m}^{2}$ at the same asphaltene equilibrium concentration of $200 \mathrm{mg} / \mathrm{L}$ [36]. This could be because of the synergistic effect of the compounds that enhances the adsorption due to the various selectivities of the adsorbent [37]. Also, bimetallic compounds have synergistic effects in avoiding sintering processes, which would lead to a less heterogeneous surface [45]. Hence, an adsorbent with various selectivities towards asphaltenes would be more efficient and will have higher affinity than that with single selectivity [46]. Also, the presence of $\mathrm{NiO}$ and PdO nanoparticles over the silica surface may inhibit the asphaltenes self-association over the catalyst surface [39].

For catalytic decomposition of the heavy molecules, the asphaltenes migrate first from the bulk phase to the nanoparticles surface. The velocity with which asphaltenes are adsorbed over the nanoparticles would depend on the adsorption potential of the selected material and this is also dependent on their chemical nature and structure. Adsorbed asphaltenes can be found in the active sites as monomers, dimers, $i$-mers or aggregates according to the crowding of the available surface area. Then, as temperature increases, the adsorbed asphaltenes are decomposed and the $\mathrm{H}_{2}$ or $\mathrm{O}_{2}$ from the $\mathrm{H}_{2} \mathrm{O}_{(\mathrm{g})}$ will react with the free radicals. It is expected that the catalytic activity of the nanoparticles would affect the way both water and asphaltenes get adsorbed on the active sites, leading to a less expensive process in energetic terms. The degree of asphaltenes self-association impacts the catalytic activity of the nanoparticles as bigger aggregates could block some active sites [47].

The $\mathrm{SiO}_{2}$ and SiNi1Pd1 nanoparticles were tested in an atmosphere of Ar saturated with $\mathrm{H}_{2} \mathrm{O}_{(\mathrm{g})}$ for asphaltenes catalytic steam gasification using thermogravimetric analyses. For virgin $n$ - $\mathrm{C}_{7}$ asphaltenes, the reaction begins approximately at $300{ }^{\circ} \mathrm{C}$, with a maximum rate of mass loss at $458^{\circ} \mathrm{C}$ and ceases at $544^{\circ} \mathrm{C}$. It is worth to mention that at the end of the reaction coke formation was observed. Meanwhile, the catalytic steam gasification of asphaltenes in the presence of $\mathrm{SiO}_{2}$ nanoparticles can be divided 
into two reaction regions. The first region $\left(<500^{\circ} \mathrm{C}\right)$ could correspond to dissociation of S-C and N-C bonds, the break-up of alkyl chains and the opening of polycyclic aromatic hydrocarbons $[33,48,49]$. In the second region, $\left(500-800{ }^{\circ} \mathrm{C}\right)$, there are reactions attributed to the gasification of resultant compounds after addition reactions of free radicals that did not stabilize in the reactions of the first region. Furthermore, for the SiNi1Pd1 nanoparticles, the maximum rate of mass loss is observed at $220{ }^{\circ} \mathrm{C}$. As it was mentioned before, bimetallic compounds avoid sintering effects and lead to homogeneous distribution on the surface, resulting in asphaltenes adsorption mainly on the $\mathrm{NiO}$ and PdO sites [50].

\subsection{Steam Injection Process Assisted by Nanoparticulated Catalysts}

The displacement tests were performed in three steps namely for evaluating the effect of nanoparticles in the oil recovery during steam injection. The first step includes the construction of base curves of oil recovery (water flooding). The second step consisted in obtaining the oil recovery curves with continuous steam injection for determined pore volumes injected of cold water equivalent (PVI CWE) until no more oil is produced. Finally, the third step was performed for obtaining the oil recovery profile with continuous steam injection in the presence of SiNi1Pd1 nanoparticles. The absolute permeability and the effective water $(\mathrm{Kw})$ and oil permeabilities (Ko) were 8.3, 6.7 and 5.5 Darcy, respectively. After the water flooding step, a total oil recovery of $40 \%$ was obtained. For the steam injection, 0.5 pore volumes (PV) of a Tween 80-containing brine was injected and soaked for $24 \mathrm{~h}$. A pressure differential of 0.23 psi was observed. Figure 1 shows the oil recovery curves with continuous steam injection in the presence and absence of the SiNi1Pd1 nanoparticles. It can be observed from Figure 1 that the oil recovery with the steam injection in the absence of nanoparticles stopped after approximately 20 PVI CWE, reaching an additional recovery of $36 \%$. Oil recovery is improved by steam injection in comparison with the water flooding due to different factors including, viscosity reduction, volatilization of light hydrocarbons, thermal expansion, a variation of the relative permeability and capillary pressure, as well as gravitational segregation [51]. From Figure 1 it can be also observed that the oil recovery increased even more in the presence of the selected nanoparticles. Similar percentages of oil recovery than that of steam injection in the absence of nanoparticles are obtained with fewer PVI CWE. After 3 PVI CWE, a recovery of 34\% was obtained. However, at 20 PVI CWE, the $82 \%$ of the oil in the porous media was recovered, representing a $127 \%$ more than that in the absence of nanoparticles. It is worth to mention that the pressure differential at the nanofluid soaking stage was estimated in 0.19 Psi.

Three main reasons influence the enhanced recovery of oil during steam injection in the presence of nanoparticles. The nanomaterials alter the system wettability to a strong water-wet condition by decorating the rock surface and hence, enhancing its preference for water [52]. In this case of steam injection in the presence of SiNi1Pd1 nanoparticles, the states of saturation at each stage (Table 1) corroborated the wettability changes of the system.

Also, the asphaltene adsorption over the injected nanoparticles contributes to increasing the oil recovery. As the asphaltene-asphaltene interactions are weaker than those of asphaltene-nanoparticle, the asphaltenes would be more prone for being in the nanoparticles surface than for being in the oil matrix $[53,54]$. Further, the asphaltene aggregation system in the oil matrix would be fragmented and individual asphaltene molecules or smaller asphaltene aggregates will diffuse through the bulk phase to the nanoparticles surface until saturation; the remaining asphaltenes in the bulk phase would reorganize and form smaller aggregates [55]. Reduction in the asphaltene aggregate directly leads to re-organization of the crude oil viscoelastic network and hence, to a diminution of the crude oil viscosity [54]. It is worth to mention that it has been demonstrated that the resins adsorption over the nanoparticles surface does not have significant interference in the asphaltenes adsorption [56].

The adsorbed asphaltenes over the nanoparticles active sites can be converted in lighter products depending on the conditions of asphaltene loading, the degree of self-association in the nanoparticles surface, chemical nature of the asphaltene molecule, temperature, chemical nature of the nanoparticles, 
among others. Hence, the conversion of asphaltenes in lighter products changes the chemical composition of crude oil and enhance the processes above that affect the oil recovery.

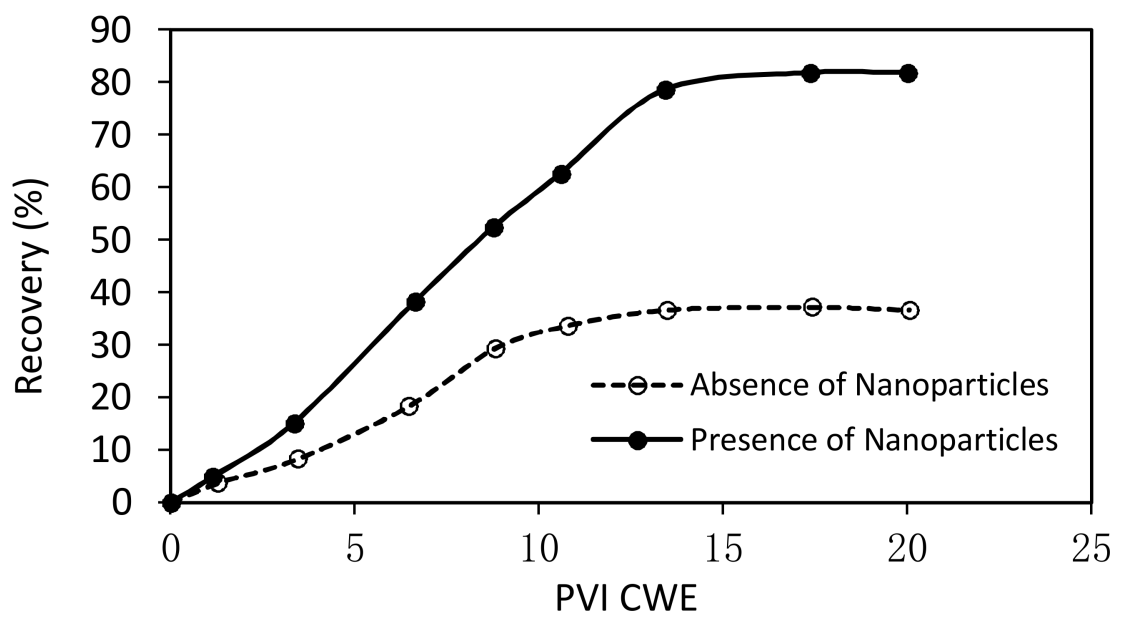

Figure 1. Oil recovery curves for cold water equivalent steam injection in the absence and presence of a nanofluid containing $500 \mathrm{mg} / \mathrm{L}$ of SiNi1Pd1 nanoparticles. Injection pressure and temperature were maintained at $8.96 \mathrm{MPa}(1300 \mathrm{psi})$ and $300^{\circ} \mathrm{C}$, respectively.

Table 1. Estimated values for residual water saturation (Swr) and residual saturation (Sor) at different stages of the displacement tests. Injection pressure and temperature were maintained at $8.96 \mathrm{MPa}$ (1300 psi) and $300^{\circ} \mathrm{C}$, respectively.

\begin{tabular}{cccc}
\hline Stage & \multirow{2}{*}{ Swr } & \multicolumn{2}{c}{ Sor } \\
\cline { 3 - 4 } & & Initial & Final \\
\hline Water flooding & $20 \%$ & $80 \%$ & $48 \%$ \\
Steam injection & $22 \%$ & $78 \%$ & $43 \%$ \\
Steam injection in the presence of nanoparticles & $25 \%$ & $75 \%$ & $24 \%$ \\
\hline
\end{tabular}

\subsection{Characterization of Upgraded Crude Oil}

\subsubsection{API Gravity, SARA and Conversion ( $\mathrm{R} \%)$}

Figure 2 shows the values of (a) saturates, aromatics, resins and asphaltene content (SARA), (b), API gravity and (c) residue $\left(620{ }^{\circ} \mathrm{C}+\right)$ conversion $(\mathrm{R} \%)$ for virgin crude oil, crude oil produced after steam injection in the absence of nanoparticles and crude oil produced after steam injection in the presence of SiNi1Pd1 nanoparticles. It can be observed from Figure 2 that the physicochemical properties of crude oil changed in both scenarios of steam injection in the absence and presence of nanoparticles. However, a higher upgrading was obtained when the SiNi1Pd1 nanoparticles were injected due to the temperature of asphaltene decomposition is reduced in comparison with the system without nanoparticles, leading to a reduction of the effective activation energy needed for the reaction $[38,41]$.

The catalytic effect of nanoparticles was observed through the decrease of $38 \%$ in asphaltene content in the presence of SiNi1Pd1 nanoparticles regarding the virgin crude oil. The increase in saturates occurred possibly from catalytic hydrogenation of aromatics and the production of light hydrocarbons throw asphaltene cracking in the presence of catalytic palladium that can adsorb on its surface 900 times its weight of hydrogen allowing the light components to form faster [57].

The increase $\mathrm{R} \%$ was achieved due to the formation of lighter compounds of crude oil, which occurs at lower temperature conditions due to the effect of nanoparticles. The residue conversion 
percentage increase $72 \%$ for crude oil produced after steam injection assisted by nanoparticles compared with the crude oil produced after steam injection and agrees with the increase in API gravity.
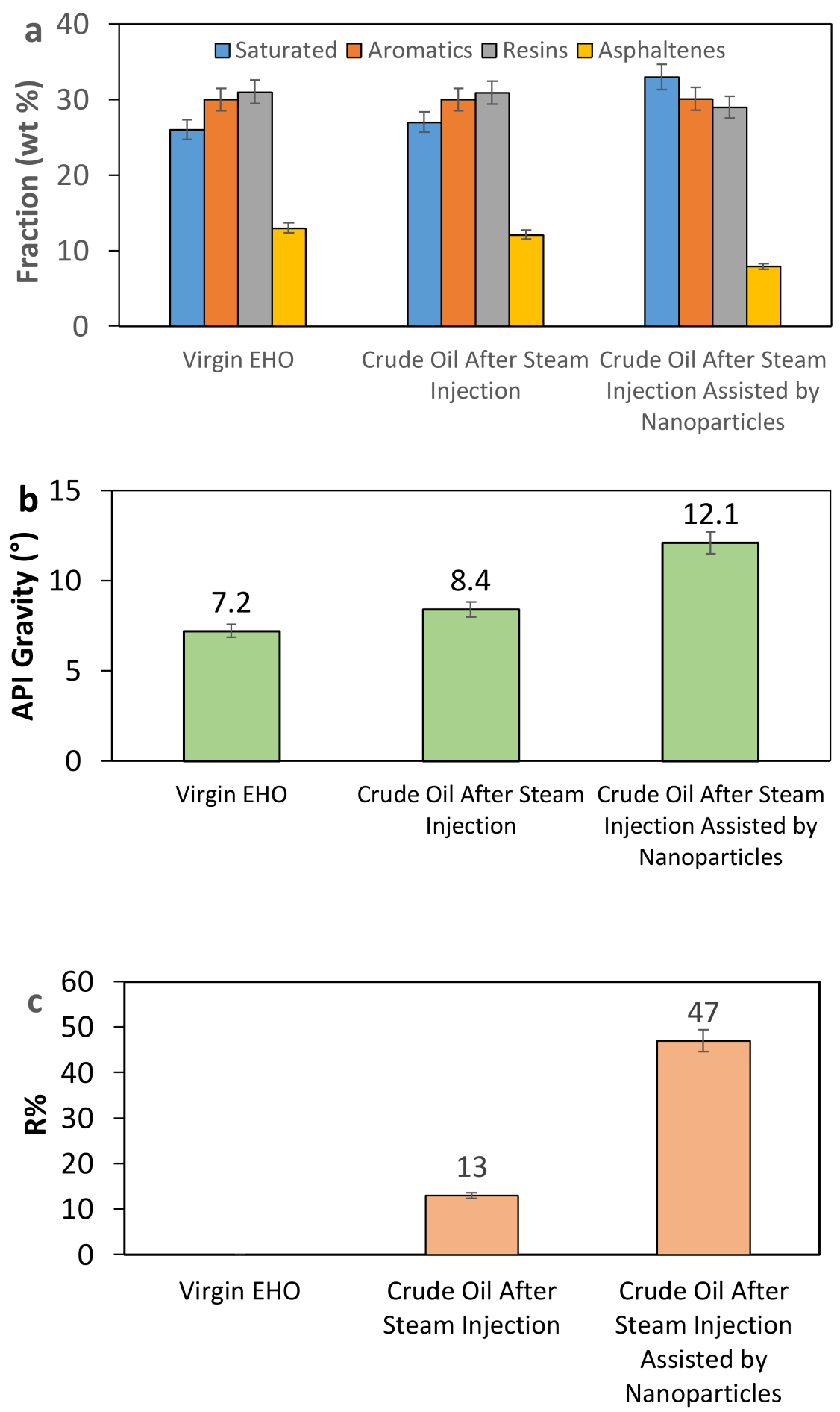

Figure 2. (a) Saturates, aromatics, resins and asphaltene content (SARA) analysis, (b) API gravity and (c) residue $\left(620^{\circ} \mathrm{C}+\right)$ conversion $(\mathrm{R} \%)$ for an extra heavy crude oil before and after recovery with steam injection in the presence and absence of $1000 \mathrm{mg} / \mathrm{L}$ of SiNi1Pd1 nanoparticles. Injection pressure and temperature were maintained at $8.96 \mathrm{MPa}(1300 \mathrm{psi})$ and $300{ }^{\circ} \mathrm{C}$, respectively. 


\subsubsection{Rheological Behavior}

Figure 3 shows the rheological behavior at $25^{\circ} \mathrm{C}$ of the virgin crude oil and the crude oil after steam injection in the presence and absence of nanoparticles, as well as the Cross model fitting. It is observed from Figure 3 that all samples have a typical non-Newtonian behavior where the viscosity decreases by increasing the share rate. Also, it can be observed that the viscosity of the crude oil after recovery with steam in the presence of the SiNi1Pd1 nanoparticles is drastically reduced in comparison to the virgin crude oil and the crude oil after steam injection in the absence of nanoparticles. At a fixed shear rate of $50 \mathrm{~s}^{-1}$, the viscosity reduction degree (VRD) [58] was $75 \%$ and $73 \%$, respectively. The heat transferred by steam in the absence of nanoparticles manages to reduce the viscosity and increases the mobility of the crude oil without upgrading, while crude oil after steam injection assisted by nanoparticles showed an improvement of the physicochemical properties of the fluid besides decreasing the viscosity.

The high viscosity of heavy and extra heavy oils is due to the formation of a viscoelastic network of interacting asphaltene nanoaggregates and resins [54,59], in addition to the presence of $C-S$ and $C=S$ bonds [60]. Hence, when nanoparticles catalytically decompose the heaviest molecules of crude oil such as asphaltenes, the viscoelastic network will be interrupted and the crude oil matrix would reorganize as the chemical structure of the bulk phase is changing. Also, the adsorption process of asphaltenes over the nanoparticles may change the rheological behavior. Taborda et al. [61] demonstrated that the sole addition of $8 \mathrm{~nm} \mathrm{SiO}{ }_{2}$ nanoparticles to the crude oil reduces the viscosity up to $55 \%$ and is mainly attributed to the changes in the internal structure of the fluid [54].

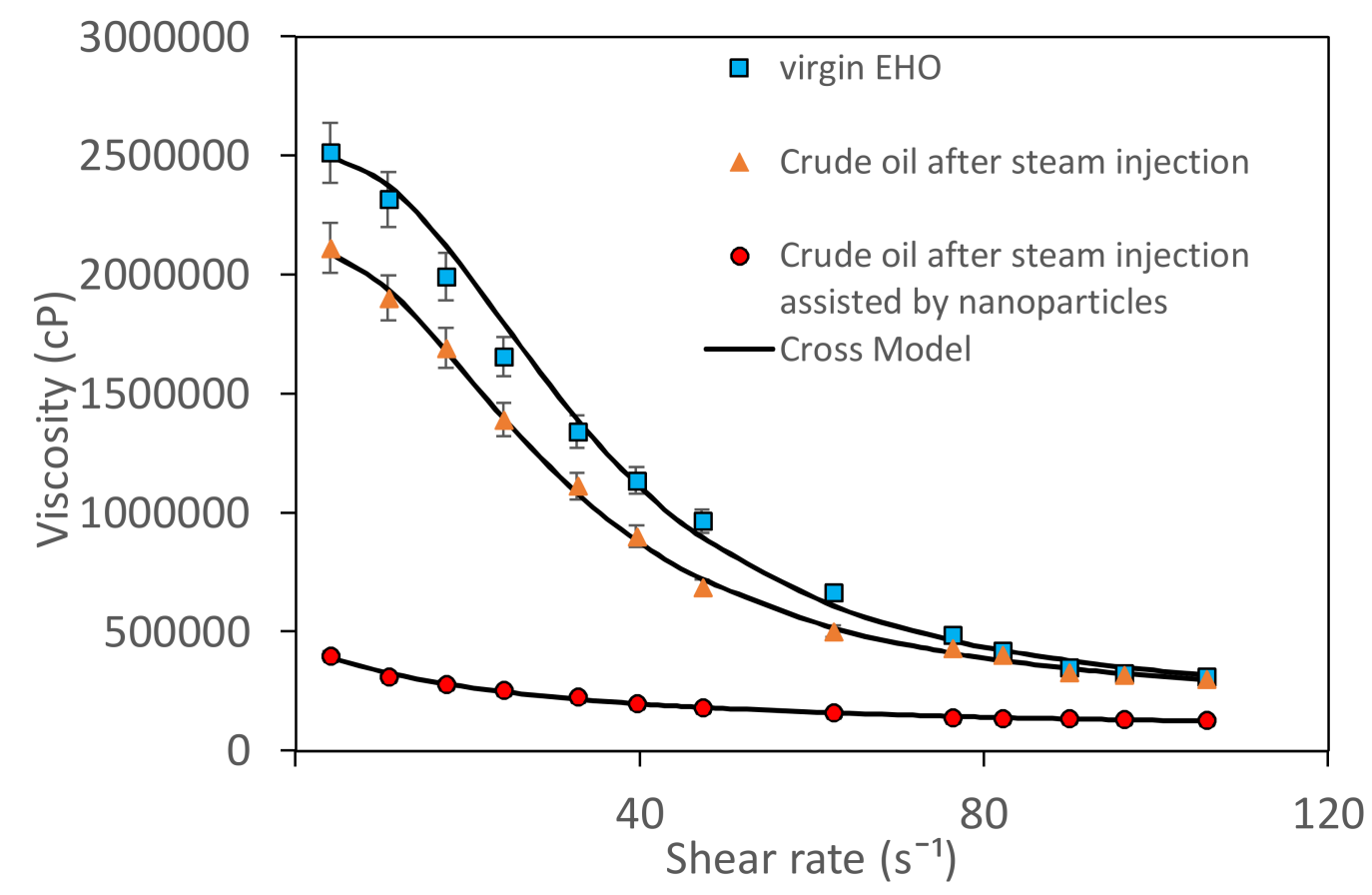

Figure 3. The rheological behavior of an extra heavy crude oil before and after recovery with steam injection in the presence and absence of $1000 \mathrm{mg} / \mathrm{L}$ of SiNi1Pd1 nanoparticles. Injection pressure and temperature were maintained at $8.96 \mathrm{MPa}(1300 \mathrm{psi})$ and $300{ }^{\circ} \mathrm{C}$, respectively. The points are the experimental data and the continuous line is the Cross model in Equation (2).

Table 2 shows the rheological parameters of the Cross and Ostwald-de Waele models for virgin $\mathrm{EHO}$, crude oil after steam injection and crude oil after steam injection assisted by SiNi1Pd1 nanoparticles at $25^{\circ} \mathrm{C}$. The model that best describes the experimental data was Cross model with $R S M E \%<7.0$. Extreme viscosity parameters $\mu(0, \gamma)$ and $\mu(\alpha, \gamma)$ account for the fluid behavior when subjected to stress at share rates of zero and infinity, respectively. The Table 2 shows that these 
parameters decrease in the order steam injection assisted by nanoparticles $>$ steam injection in the absence of nanoparticles > virgin EHO, indicating that the mobility properties of the fluid are enhanced by the presence of nanoparticles. Also, it is observed that $\alpha_{C}$ is lowest for the crude oil recovered after steam injection in the presence of nanoparticles, indicating that the treatment leads to less pseudoplastic behavior of the crude oil. These results of viscosity reduction are of primary significance as demonstrate that the mobility of crude oil can be enhanced at both surface and subsurface conditions.

Table 2. Rheological parameters of the Cross and Ostwald-de Waele models for virgin extra heavy crude oils (EHO), crude oil after steam injection and crude oil after steam injection assisted by SiNi1Pd1 nanoparticles at $25^{\circ} \mathrm{C}$.

\begin{tabular}{ccccc}
\hline Model & Parameters & Virgin EHO & $\begin{array}{c}\text { Crude Oil after } \\
\text { Steam Injection }\end{array}$ & $\begin{array}{c}\text { Crude Oil after Steam } \\
\text { Injection Assisted } \\
\text { by Nanoparticles }\end{array}$ \\
\hline \multirow{2}{*}{ Cross } & $\mu_{\propto, \gamma}(\mathrm{cP})$ & 180 & 178 & 68 \\
& $\mu_{0, \gamma}(\mathrm{cP})$ & 2512 & 2113 & 435 \\
& $\alpha_{C}\left(\mathrm{~s} \times 10^{-2}\right)$ & 3.6 & 3.1 & 1.88 \\
& $m$ & 2.42 & 2.19 & 1.12 \\
\hline Ostwald-de Waele & $R S M \%$ & 6.2 & 3.1 & 3.0 \\
& $K(\mathrm{cP} / \mathrm{s})$ & $2.5 \times 10^{7}$ & $2.2 \times 10^{7}$ & $7.2 \times 10^{6}$ \\
& $n$ & 0.13 & 0.09 & 0.09 \\
& 16.9 & 19.5 & 11.1 \\
\hline
\end{tabular}

\section{Materials and Methods}

\subsection{Materials}

Fumed silica $\left(\mathrm{SiO}_{2}\right)$ nanoparticles were purchased from Sigma-Aldrich (St. Louis, MO, USA). Salt precursors of $\mathrm{Ni}\left(\mathrm{NO}_{3}\right)_{2} \cdot\left(6 \mathrm{H}_{2} \mathrm{O}\right)$ (Merck KGaA, Darmstadt, Germany) and $\mathrm{Pd}\left(\mathrm{NO}_{3}\right)_{2}$ (Merck KGaA, Darmstadt, Germany) and distilled water were used for nanoparticle functionalization. The functionalized nanoparticles were synthesized following the procedure reported in a previous study [37].

Deionized water with conductivity of $3 \mu \mathrm{S} / \mathrm{cm}$ was employed for steam generation, as well as for brine and nanofluid preparation. A $2000 \mathrm{mg} / \mathrm{L}$ of $\mathrm{NaCl}$ ( $\geq 99.5 \%$, Merck KGaA, Darmstadt, Germany) synthetic brine was employed for injection into the porous media. Commercial surfactant Tween 80 (Panreac, Barcelona, Spain) was employed for nanoparticles dispersion. A Colombian EHO of $7.2^{\circ}$ API was used for the displacement tests. The porous media was prepared with clean silica sand (Ottawa sand, US sieves 30-40 mesh) purchased from Minercol S.A. (Colombia). Also, toluene (99.8\%, Panreac, Barcelona, Spain), methanol (99.8\%, Panreac, Barcelona, Spain) and $\mathrm{HCl}$ (37\%, Panreac, Barcelona, Spain) were used for porous media cleaning.

\subsubsection{Nanoparticles Characterization}

Nanoparticles were characterized by way of Brunauer-Emmett-Teller (BET) surface area $\left(\mathrm{S}_{\mathrm{BET}}\right)$, mean crystallite size and percentage of metal oxide nanoparticles coverage over the support. The $\mathrm{S}_{\mathrm{BET}}$ was measured via nitrogen physisorption at $-196^{\circ} \mathrm{C}$ using an Autosorb- 1 from Quantachrome after outgassing samples overnight at $140{ }^{\circ} \mathrm{C}$ under high vacuum. The nanoparticles mean crystallite size was measured through the Scherrer equation to the primary X-ray Diffraction (XRD) peak. XRD patterns were obtained using an X'Pert PRO MPD X-ray diffractometer from PANalytical using $\mathrm{Cu} K \alpha$ radiation operating at $60 \mathrm{kV}$ and $40 \mathrm{~mA}$ with a $\theta / 2 \theta$ goniometer. The average metal particles sizes and the determination of metal dispersion over the $\mathrm{SiO}_{2}$ support was evaluated by pulse chemisorption trough $\mathrm{H}_{2}$ titration using a Chembet 3000 (Quantachrome Instruments, Boynton Beach, FL, USA). Fist, the SiNi1Pd1 catalysts were dried at $200{ }^{\circ} \mathrm{C}$ for $1 \mathrm{~h}$ and then reduced at $700{ }^{\circ} \mathrm{C}$ for $1 \mathrm{~h}$ in $10 \mathrm{vol} \% \mathrm{H}_{2}$ in Ar at $80 \mathrm{~mL} / \mathrm{min}$ and purged with flowing bAr for $1 \mathrm{~h}$ until the samples reach atmosphere temperature of $25^{\circ} \mathrm{C}$. The hydrogen pulses continued until no additional uptake of $\mathrm{H}_{2}$ was observed. The particle 
size of the synthesized materials was obtained by dynamic light scattering (DLS) with a nanoplus-3 from Micromeritics (Norcross, GA, USA) [53,55].

\subsubsection{Porous Media}

A solution of methanol and toluene in a 1:1 ratio was employed for the initial cleaning of the prepared porous bed using a concentration of $10 \mathrm{~mL}$ per $5 \mathrm{~g}$ of sand. Then, the sand was washed with $\mathrm{HCl}$ at $10 \mathrm{vol} / \mathrm{wt} \%$ to remove any surface impurities or dust and finally dried in a vacuum oven at $120^{\circ} \mathrm{C}$ for $12 \mathrm{~h}$. Approximately $100 \mathrm{~g}$ of the sand are transferred to a stainless-steel tube and the porous media permeability was estimated following Darcy's law.

\subsubsection{Preparation of Nanofluid}

The nanofluid was prepared by dispersing $500 \mathrm{mg} / \mathrm{L}$ of SiNi1Pd1 nanoparticles in a $1 \mathrm{wt} \%$ solution of tween $80 \mathrm{in}$ distilled. The nanofluid is magnetically stirred at $300 \mathrm{rpm}$ at $25^{\circ} \mathrm{C}$ for $6 \mathrm{~h}$ and then sonicated for $4 \mathrm{~h}$ [62].

\subsection{Methods}

\subsubsection{Selection of Catalytic Nanoparticles}

Bath-mode adsorption experiments were carried out at a temperature of $25{ }^{\circ} \mathrm{C}$ using a set of $50-\mathrm{mL}$ glass beakers by adding a fixed amount of nanoparticles to the heavy oil model solutions for an adsorbent to solution ratio of $100 \mathrm{mg}$ to $10 \mathrm{~mL}$ and different initial concentrations of $n$ - $C_{7}$ asphaltenes as described in previous works $[37,50]$. After that, the nanoparticles containing adsorbed asphaltenes were dried to remove any traces of toluene. Amount adsorbed was determined using an UV-Vis Genesys $10 \mathrm{~S}$ spectrophotometer (Thermo Scientific, Waltham, MA, USA) [63]. At this stage, the nanoparticles containing adsorbed asphaltenes were ready for the thermal analysis experiment. To evaluate the catalytic behavior of the selected nanoparticles, catalytic steam gasification of adsorbed asphaltenes over nanoparticles was carried out and studied using a simultaneous thermogravimetric analysis, TGA Q50 analyzer (TA Instruments, Inc., New Castle, DE, USA) coupled with an IRAffinity-1 FTIR device (Shimadzu, Japan) to analyze the outcome gases [36]. The amount of asphaltene adsorbed was fixed at $0.20 \pm 0.02 \mathrm{mg} / \mathrm{m}^{2}$ and was heated from 100 to $900{ }^{\circ} \mathrm{C}$ at three different heating rates of 5 , 10 and $20^{\circ} \mathrm{C} / \mathrm{min}$ in an atmosphere of Ar saturated with and $\mathrm{H}_{2} \mathrm{O}_{(\mathrm{g})}$. This flow rate allows the steam to be present above the sample in excess [35]. Details of TGA experiments can be found in a previous study [64].

\subsubsection{Fluid Injection Test}

The main objective of the displacement tests was to evaluate the effect of the nanoparticles in enhancing the oil recovery with continuous steam injection and upgrading the produce crude oil. Figure 4 shows a schematic representation of the experimental setup employed for the displacement tests. The setup consists mainly of a positive displacement pump (DB Robinson Group, Edmonton, $\mathrm{AB}, \mathrm{Canada}$ ), a cylinder containing water for steam generation, a tubular furnace (Thermo Scientific, Waltham, MA, USA), an oil-containing cylinder, a tank containing the nanofluid, a stainless-steel tube, manometers, a thermocouple, valves and fraction collectors. The porous media has a porosity of $38 \%$. The nanofluid was injected into the porous media from the production point using the positive displacement pump. The temperature of the surroundings was kept at $85^{\circ} \mathrm{C}$ for all steps using an oven. The displacement test was performed in three steps. First, the oil recovery base curves by water injection are obtained. In the second step, the oil recovery by the continuous steam injection in the absence of nanofluids is measured. Finally, the third step consisted in evaluating the influence of the nanoparticles in the enhanced recovery of oil. For absolute permeability estimation, 10 pore volumes $(\mathrm{PV})$ of brine was injected into the porous media at a defined rate of $0.5 \mathrm{~mL} / \mathrm{min}$. Subsequently, the crude oil was injected until the pressure no longer changed and then $20 \mathrm{PV}$ of water are injected for 
determining the water effective permeability $(\mathrm{Kw})$ at residual oil saturation (Sor) conditions. For step two, the steam was introduced into the sand from the water cylinder through the coil line and pressure and temperature conditions were recorded. The water was injected at a flow ranging between 2.5 and $6.5 \mathrm{~mL} / \mathrm{min}$ to avoid condensation after in the outlet of the coil line. The conditions injection pressure and temperature were maintained at $8.96 \mathrm{MPa}(1300 \mathrm{psi})$ and $300{ }^{\circ} \mathrm{C}$ for ensuring a steam quality of $100 \%$. It is expected that at a high $n-C_{7}$ asphaltene conversion would be obtained a temperature of $300{ }^{\circ} \mathrm{C}$ in the presence of SiNi1P1 nanoparticles $[37,39,41,50]$. It is worth to mention that for step two, $0.5 \mathrm{PV}$ of a mixture of a $2000 \mathrm{mg} / \mathrm{L} \mathrm{NaCl}$ brine $+1 \mathrm{wt} \%$ tween 80 was injected into the porous media as blank. In step three, $0.5 \mathrm{PV}$ of nanofluid were injected at a fixed rate of $0.5 \mathrm{~mL} / \mathrm{min}$ by the production inlet with a soaking time of $24 \mathrm{~h}$. Finally, steam was injected at the same conditions than that of step two until there was no oil production.

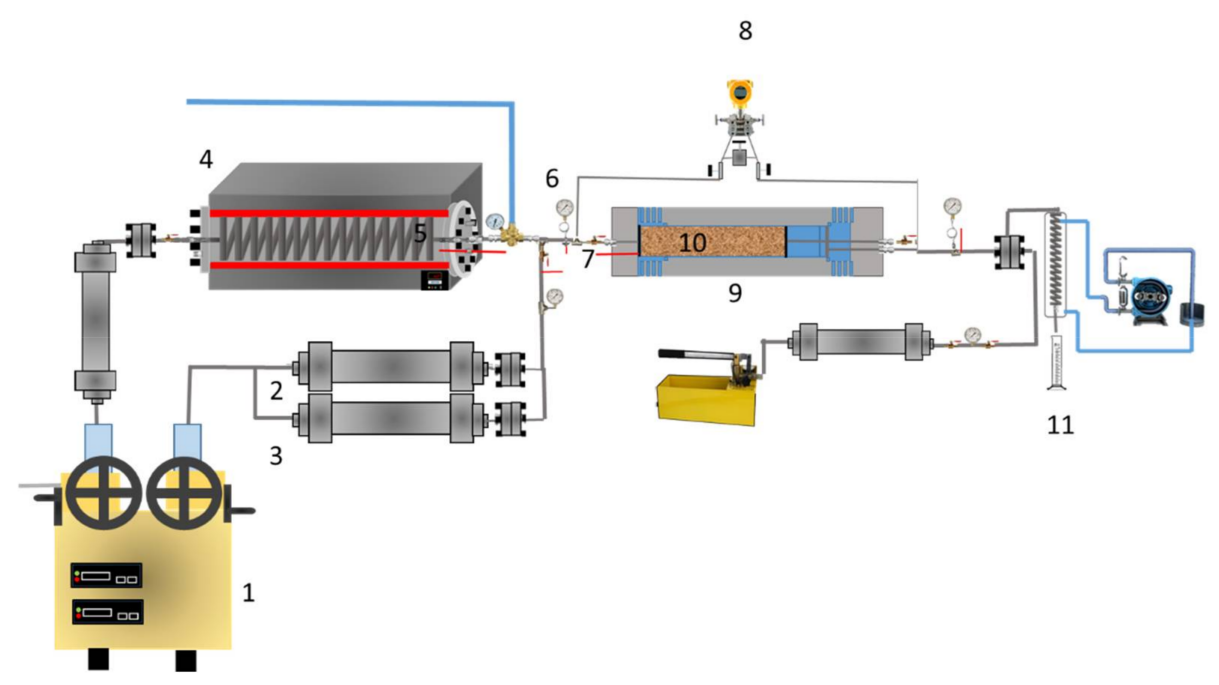

Figure 4. Schematic representation of the experimental setup. Legend: (1) the displacement positive pumps the core holder, (2) the oil-containing displacement cylinder, (3) the water-containing displacement cylinder, (4) the tubular furnace (5) the coil line (6) the manometers, (7) the thermocouple, (8) the pressure transducer, (9) the slim tube, (10) the sand packed bed and (11) sample output.

\subsubsection{Analytical Methods}

Changes in API gravity, oil viscosity, saturates, aromatics, resins and asphaltene content (SARA), as well as residue content $\left(620^{\circ} \mathrm{C}+\right)$ were estimated to determine the effect of the nanoparticles in the EHO upgrading after recovery with steam injection in the presence of nanoparticles. The oil sample for analytical tests was the one taken when each step of the displacement test ended. The ASTM D1298 standard was used to determine the changes in the API gravity. For SARA analyses, micro de-asphalting was performed to the crude oil by $n$-heptane. The content of saturates, aromatics and resins were obtained through IATROSCAN MK6 TLC-FID/FPD equipment with hydrogen injection using the IP 469 method. The residue content $\left(620^{\circ} \mathrm{C}+\right)$ was estimated using high-temperature simulated distillation (HTSD) following the ASTM D-7169 procedure using an Agilent 7890 chromatographer. Results are presented as residue conversion $(R \%)$ as follows [31]:

$$
R \%=\frac{R_{\text {virginEHO }}-R_{\text {Treatment }}}{R_{\text {virginEHO }}} \times 100
$$

where $R_{\text {virginEHO }}$ and $R_{\text {Treatment }}$ is the residue content before and after steam injection, respectively.

The rheological behavior of crude oil was evaluated at $25^{\circ} \mathrm{C}$ using a KINEXUS-Pro + rheometer with separated plate-plate geometry ideal for heavy oil. Different shear rates in a range from 0 to $100 \mathrm{~s}^{-1}$ were used for viscosity measurement. 


\subsubsection{Rheological Models}

Empirical models of Cross and Ostwald-de Waele [65] were employed to describe Non-Newtonian

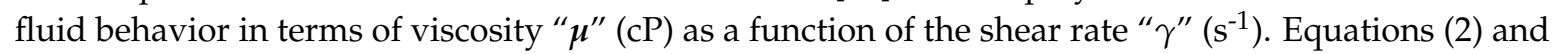
(3) show the expressions for the Cross and Ostwald-de Waele models, respectively:

$$
\begin{gathered}
\mu=\mu_{\infty, \gamma}+\frac{\mu_{o, \gamma}-\mu_{\infty, \gamma}}{1+\left(\alpha_{c} \gamma\right)^{m}} \\
\mu=K\left(\gamma^{(n-1)}\right)
\end{gathered}
$$

For the Cross model, $\alpha_{c}(\mathrm{~s})$ is the characteristic relaxion time, $m$ is a constant related to the flow behavior, and $\mu_{\infty, \gamma}(\mathrm{cP})$ and $\mu_{0, \gamma}(\mathrm{cP})$ are the viscosities at infinite shear rate and zero shear rate, respectively. In the case of the Ostwald-de Waele model, $K(\mathrm{cP} / \mathrm{s})$ is the consistency index and $n$ is the flow behavior index.

To define the model that best fits the experimental data, the root-mean-square error ( $R S M E \%)$ was used:

$$
R S M E \%=100 \sqrt{\frac{1}{k}\left[\sum_{1}^{k}\left[\frac{C \exp -C \operatorname{Cal}}{C \exp }\right]^{2}\right]}
$$

where $C \exp$ is the experimental measure of viscosity, Ccal is the viscosity calculated by the employed models and $k$ the number of experimental points.

\section{Conclusions}

The advantages of nanotechnology as solution for extra heavy oil upgrading and enhanced oil recovery is shown in this work. In the adsorption process, functionalized nanoparticles are prone to reduce the degree of asphaltene self-association and increase the adsorption affinity [37,41]. Nanoparticles also are able to enhance the asphaltene catalytic steam gasification process by reducing the degree of asphaltene self-association over the catalyst surface, decreasing the temperature of asphaltenes decomposition and by the inhibition of the coke formation and the catalyst poisoning [41,50]. It was observed that the oil recovery increased up to $56 \%$ for the system in the presence of SiNi1Pd1 nanoparticles regarding the steam injection in the absence of the nanocatalyst. Additionally, trough API gravity, viscosity, SARA analyses and residue content measurements it was demonstrated that nanoparticles upgrade the quality of extra heavy oils during steam injection processes. The API gravity of crude oil increased from $7.2^{\circ}$ to $12.1^{\circ}$. A reduction of oil viscosity was also observed. $n-C_{7}$ asphaltene content decreased a $39 \%$ after steam injection in the presence of nanoparticles in comparison with the untreated EHO. Also, the residue content $\left(620^{\circ} \mathrm{C}+\right)$ decreased a $47 \%$. The rheological behavior of the crude oil showed a less pseudoplastic trend after injection of steam in the presence of the selected nanoparticles. The improvement of oil recovery due to the inclusion of catalytic nanoparticles could be attributed to mainly to wettability alteration, viscosity reduction due to disruption of the viscoelastic network and crude oil upgrading. This study should generate a better landscape about the use of catalytic nanoparticles in the improvement of enhanced oil recovery processes and its application in local and international scenarios.

Acknowledgments: The authors acknowledge COLCIENCIAS and Agencia Nacional de Hidrocarburos (Colombia) for their support provided through the 272-2017 agreement. They also acknowledge the Universidad Nacional de Colombia for logistical and financial support.

Author Contributions: All authors conceived and designed the experiments; L.C., D.A.M. and C.A.F. performed the experiments; All authors analyzed the data; F.B.C. and S.H.L. contributed reagents/materials/analysis tools; All authors wrote the paper.

Conflicts of Interest: The authors declare no conflict of interest. 


\section{References}

1. Tedeschi, M. [13] Reserves and production of Heavy Crude Oil and Natural Bitumen. In Proceedings of the 13th World Petroleum Congress, Buenos Aires, Argentina, 20-25 October 1991.

2. IEA. Resources to Reserves 2013. 2013. Available online: http:/ /www.iea.org/etp/resourcestoreserves/ (accessed on 25 March 2018).

3. IEA. World Energy Investment Outlook. 2014. Available online: https://www.iea.org/newsroom/news / 2014/november/world-energy-outlook-2014.html (accessed on 25 March 2018).

4. Gurgel, A.; Moura, M.; Dantas, T.; Neto, E.B.; Neto, A.D. A review on chemical flooding methods applied in enhanced oil recovery. Braz. J. Pet. Gas 2008, 2, 83-95.

5. Barillas, J.; Júnior, T.D.; Mata, W. Improved oil recovery process for heavy oil: A review. Braz. J. Pet. Gas 2008, 2, 45-54.

6. Green, D.W.; Willhite, G.P.; Henry, L. Enhanced Oil Recovery; Doherty Memorial Fund of AIME, Society of Petroleum Engineers Richardson: Richardson, TX, USA, 1998; Volume 6.

7. Ageeb, A.A.; Al-siddig, M.H.; Nor-aldeen, M.R.; Soliman, M.S.; Ibrahim, I.H. The Influence of Steam Injection Volume on Sand and Oil Production in Cyclic Steam Stimulation (CSS) Wells; Sudan University of Science and Technology: Khartoum, Sudan, 2017.

8. Dietrich, J. Relative Permeability During Cyclic Steam Stimulation of Heavy-Oil Reservoirs. J. Pet. Technol. 1981, 33, 1987-1989. [CrossRef]

9. Alvarez, J.; Han, S. Current overview of cyclic steam injection process. J. Pet. Sci. Res. 2013, 2, $116-127$.

10. Allen, J.C.; Porter, J.W. Steam Flooding Hydrocarbon Recovery Process. U.S. Patent 4,133,384, 9 June 1979.

11. Shu, W.R.; Hartman, K.J. Thermal Recovery Method for Viscous Oil. U.S. Patent 4,598,770, 8 July 1986.

12. Sheng, J.J. Cyclic steam stimulation. In Enhanced Oil Recovery Field Case Studies; Elsevier: Amsterdam, The Netherlands, 2013; pp. 389-412.

13. Parrish, D.R. Recovery of Hydrocarbons by Thermal Methods. U.S. Patent 3,332,480, 25 July 1967.

14. Luo, P.; Yang, C.; Tharanivasan, A.; Gu, Y. In situ upgrading of heavy oil in a solvent-based heavy oil recovery process. J. Can. Pet. Technol. 2007, 46, 37-43. [CrossRef]

15. Cavallaro, A.; Galliano, G.; Sim, S.; Singhal, A.; Fisher, D. Laboratory investigation of an innovative solvent based enhanced recovery and in situ upgrading technique. In Proceedings of the Canadian International Petroleum Conference, Calgary, AB, Canada, 7-9 June 2005.

16. Jiang, S.; Liu, X.; Liu, Y.; Zhong, L. In situ upgrading heavy oil by aquathermolytic treatment under steam injection conditions. In Proceedings of the SPE International Symposium on Oilfield Chemistry, The Woodlands, Texas, 2-4 February 2005.

17. Fan, H.; Zhang, Y.; Lin, Y. The catalytic effects of minerals on aquathermolysis of heavy oils. Fuel 2004, 83, 2035-2039. [CrossRef]

18. Maity, S.; Ancheyta, J.; Marroquín, G. Catalytic aquathermolysis used for viscosity reduction of heavy crude oils: A review. Energy Fuels 2010, 24, 2809-2816. [CrossRef]

19. Speight, J. Thermal cracking of Athabasca bitumen, Athabasca asphaltenes, and Athabasca deasphalted heavy oil. Fuel 1970, 49, 134-145. [CrossRef]

20. Kumar, J.; Fusetti, L.; Corre, B. Modeling In-Situ Upgrading of Extraheavy Oils/Tar Sands by Subsurface Pyrolysis. In Proceedings of the Canadian Unconventional Resources Conference, Calgary, AB, Canada, 15-17 November 2011.

21. Monin, J.; Audibert, A. Thermal cracking of heavy-oil/mineral matrix systems. SPE Reserv. Eng. 1988, 3, 1243-1250. [CrossRef]

22. Nassar, N.N.; Hassan, A.; Luna, G.; Pereira-Almao, P. Comparative study on thermal cracking of Athabasca bitumen. J. Therm. Anal. Calorim. 2013, 114, 465-472. [CrossRef]

23. Moore, R.; Laureshen, C.; Mehta, S.; Ursenbach, M.; Belgrave, J.; Weissman, J.; Kessler, R. A downhole catalytic upgrading process for heavy oil using in situ combustion. J. Can. Pet. Technol. 1999, 38. [CrossRef]

24. Cavallaro, A.; Galliano, G.; Moore, R.; Mehta, S.; Ursenbach, M.; Zalewski, E.; Pereira, P. In situ upgrading of Llancanelo heavy oil using in situ combustion and a downhole catalyst bed. J. Can. Pet. Technol. 2008, 47, 23-31. 
25. Xu, H.H.; Okazawa, N.; Moore, R.; Mehta, S.; Laureshen, C.; Ursenbach, M.; Mallory, D. In situ upgrading of heavy oil. In Proceedings of the Canadian International Petroleum Conference, Calgary, AB, Canada, 4-8 June 2000.

26. Wichert, G.; Okazawa, N.; Moore, R.; Belgrave, J. In-Situ Upgrading of Heavy Oils by Low-Temperature Oxidation in the Presence of Caustic Additives. In Proceedings of the International Heavy Oil Symposium, Calgary, AB, Canada, 19-21 June 1995; pp. 529-536.

27. Butler, R. SAGD comes of age! J. Can. Pet. Technol. 1998, 37. [CrossRef]

28. Nasr, T.; Beaulieu, G.; Golbeck, H.; Heck, G. Novel expanding solvent-SAGD process ES-SAGD. J. Can. Pet. Technol. 2003, 42, 13-16. [CrossRef]

29. Hashemi, R.; Nassar, N.N.; Pereira Almao, P. Enhanced heavy oil recovery by in situ prepared ultradispersed multimetallic nanoparticles: A study of hot fluid flooding for Athabasca bitumen recovery. Energy Fuels 2013, 27, 2194-2201. [CrossRef]

30. Hashemi, R.; Nassar, N.N.; Almao, P.P. Nanoparticle technology for heavy oil in-situ upgrading and recovery enhancement: Opportunities and challenges. Appl. Energy 2014, 133, 374-387. [CrossRef]

31. Hashemi, R.; Nassar, N.N.; Pereira-Almao, P. Transport behavior of multimetallic ultradispersed nanoparticles in an oil-sands-packed bed column at a high temperature and pressure. Energy Fuels 2012, 26, 1645-1655. [CrossRef]

32. Galarraga, C.E.; Pereira-Almao, P. Hydrocracking of Athabasca bitumen using submicronic multimetallic catalysts at near in-reservoir conditions. Energy Fuels 2010, 24, 2383-2389. [CrossRef]

33. Hamedi Shokrlu, Y.; Babadagli, T. In-situ upgrading of heavy oil/bitumen during steam injection by use of metal nanoparticles: A study on in-situ catalysis and catalyst transportation. SPE Reserv. Eval. Eng. 2013, 16, 333-344. [CrossRef]

34. Hosseinpour, N.; Khodadadi, A.A.; Bahramian, A.; Mortazavi, Y. Asphaltene adsorption onto acidic/basic metal oxide nanoparticles toward in situ upgrading of reservoir oils by nanotechnology. Langmuir 2013, 29, 14135-14146. [CrossRef] [PubMed]

35. Nassar, N.N.; Hassan, A.; Pereira-Almao, P. Application of Nanotechnology for Heavy Oil Upgrading: Catalytic Steam Gasification/Cracking of Asphaltenes. Energy Fuels 2011, 25, 1566-1570. [CrossRef]

36. Franco, C.A. Franco, C. Synthesis and Application of Supported Metallic and Multi-Metallic Oxides Nanoparticles for in-Situ Upgrading and Inhibition of Formation Damage; Universidad Nacional de Colombia-Sede Medellín: Medellín, Antioquia, Colombia, 2015.

37. Franco, C.A.; Montoya, T.; Nassar, N.N.; Pereira-Almao, P.; Cortés, F.B. Adsorption and subsequent oxidation of colombian asphaltenes onto Nickel and/or Palladium oxide supported on fumed silica nanoparticles. Energy Fuels 2013, 27, 7336-7347. [CrossRef]

38. Montoya, T.; Argel, B.L.; Nassar, N.N.; Franco, C.A.; Cortés, F.B. Kinetics and mechanisms of the catalytic thermal cracking of asphaltenes adsorbed on supported nanoparticles. Pet. Sci. 2016, 13, 561-571. [CrossRef]

39. Nassar, N.N.; Franco, C.A.; Montoya, T.; Cortés, F.B.; Hassan, A. Effect of oxide support on Ni-Pd bimetallic nanocatalysts for steam gasification of $n-C_{7}$ asphaltenes. Fuel 2015, 156, 110-120. [CrossRef]

40. Franco, C.; Patiño, E.; Benjumea, P.; Ruiz, M.A.; Cortés, F.B. Kinetic and thermodynamic equilibrium of asphaltenes sorption onto nanoparticles of nickel oxide supported on nanoparticulated alumina. Fuel 2013, 105, 408-414. [CrossRef]

41. Franco, C.A.; Nassar, N.N.; Montoya, T.; Cortés, F.B. NiO and PdO Supported on Fumed Silica Nanoparticles for Adsorption and Catalytic Steam Gasification of Colombian C7-Asphaltenes; Nova Science Publishers: Hauppauge, New York, NY, USA, 2014; p. 46.

42. Farooqui, J.; Babadagli, T.; Li, H.A. Improvement of the recovery factor using nano-metal particles at the late stages of cyclic steam stimulation. In Proceedings of the SPE Canada Heavy Oil Technical Conference, Calgary, AB, Canada, 9-11 June 2015.

43. Yi, S.; Babadagli, T.; Li, H.A. Use of Nickel Nanoparticles for Promoting Aquathermolysis Reaction During Cyclic Steam Stimulation. SPE J. 2017, 23. [CrossRef]

44. Afzal, S.; Nikookar, M.; Ehsani, M.R.; Roayaei, E. An experimental investigation of the catalytic effect of $\mathrm{Fe}_{2} \mathrm{O}_{3}$ nanoparticle on steam injection process of an Iranian reservoir. Iran. J. Oil Gas Sci.Technol. 2014, 3, 27-36.

45. Contreras, J.L.; Fuentes, G.A. Sintering of Supported Metal Catalysts; InTechOpen: Rijeka, Croatia, $2012 ;$ p. 93. 
46. Cheng, B.; Le, Y.; Cai, W.; Yu, J. Synthesis of hierarchical $\mathrm{Ni}(\mathrm{OH})_{2}$ and $\mathrm{NiO}$ nanosheets and their adsorption kinetics and isotherms to Congo red in water. J. Hazard. Mater. 2011, 185, 889-897. [CrossRef] [PubMed]

47. Dabrowski, A. Adsorption-From theory to practice. Adv. Colloid Interface Sci. 2001, 93, 135-224. [CrossRef]

48. Nassar, N.N.; Hassan, A.; Pereira-Almao, P. Thermogravimetric studies on catalytic effect of metal oxide nanoparticles on asphaltene pyrolysis under inert conditions. J. Thermal Anal. Calorim. 2011, 110, 1327-1332. [CrossRef]

49. Siddiqui, M.N. Catalytic pyrolysis of Arab Heavy residue and effects on the chemistry of asphaltene. J. Anal. Appl. Pyrolysis 2010, 89, 278-285. [CrossRef]

50. Franco, C.A.; Nassar, N.N.; Montoya, T.; Ruíz, M.A.; Cortés, F.B. Influence of Asphaltene Aggregation on the Adsorption and Catalytic Behavior of Nanoparticles. Energy Fuels 2015, 29, 1610-1621. [CrossRef]

51. Wu, C.H. A critical review of steamflood mechanisms. In Proceedings of the SPE California Regional Meeting, Bakersfield, CA, USA, 13-15 April 1977.

52. Giraldo, J.; Benjumea, P.; Lopera, S.; Cortés, F.B.; Ruiz, M.A. Wettability alteration of sandstone cores by alumina-based nanofluids. Energy Fuels 2013, 27, 3659-3665. [CrossRef]

53. Betancur, S.; Carmona, J.C.; Nassar, N.N.; Franco, C.A.; Cortés, F.B. Role of particle size and surface acidity of silica gel nanoparticles in inhibition of formation damage by asphaltene in oil reservoirs. Ind. Eng. Chem. Res. 2016, 55, 6122-6132. [CrossRef]

54. Taborda, E.A.; Alvarado, V.; Franco, C.A.; Cortés, F.B. Rheological demonstration of alteration in the heavy crude oil fluid structure upon addition of nanoparticles. Fuel 2017, 189, 322-333. [CrossRef]

55. Nassar, N.N.; Betancur, S.; Acevedo, S.A.; Franco, C.; Cortés, F.B. Development of a Population Balance Model to Describe the Influence of Shear and Nanoparticles on the Aggregation and Fragmentation of Asphaltene Aggregates. Ind. Eng. Chem. Res. 2015, 54, 8201-8211. [CrossRef]

56. Franco, C.A.; Lozano, M.M.; Acevedo, S.A.; Nassar, N.N.; Cortés, F.B. Effects of Resin I on Asphaltene Adsorption onto Nanoparticles: A novel method for obtaining Asphaltenes/Resins Isotherms. Energy Fuels 2015, 30, 264-272. [CrossRef]

57. Bruzzoni, P.; Carranza, R.; Collet-Lacoste, J. Adsorción de Hidrógeno en Superficies de Paladio. In Proceedings of the Jornadas SAM-SCHMM-AAS, Posadas, Argentina, 12-14 September 2001.

58. Hasan, S.W.; Ghannam, M.T.; Esmail, N. Heavy crude oil viscosity reduction and rheology for pipeline transportation. Fuel 2010, 89, 1095-1100. [CrossRef]

59. Taborda, E.A.; Franco, C.A.; Lopera, S.H.; Alvarado, V.; Cortés, F.B. Effect of nanoparticles/nanofluids on the rheology of heavy crude oil and its mobility on porous media at reservoir conditions. Fuel 2016, 184, 222-232. [CrossRef]

60. Mullins, O.C.; Sabbah, H.; Eyssautier, J.; Pomerantz, A.E.; Barré, L.; Andrews, A.B.; Ruiz-Morales, Y.; Mostowfi, F.; McFarlane, R.; Goual, L. Advances in asphaltene science and the Yen-Mullins model. Energy Fuels 2012, 26, 3986-4003. [CrossRef]

61. Taborda, E.A.; Franco, C.A.; Ruiz, M.A.; Alvarado, V.; Cortés, F.B. Experimental and theoretical study of viscosity reduction in heavy crude oils by addition of nanoparticles. Energy Fuels 2017, 31, 1329-1338. [CrossRef]

62. Franco, C.A.; Nassar, N.N.; Ruiz, M.A.; Pereira-Almao, P.; Cortés, F.B. Nanoparticles for inhibition of asphaltenes damage: Adsorption study and displacement test on porous media. Energy Fuels 2013, 27, 2899-2907. [CrossRef]

63. Guzmán, J.D.; Pineda, D.; Franco, C.A.; Botero, Ó.F.; Lopera, S.H.; Cortés, F.B. Effect of nanoparticle inclusion in fracturing fluids applied to tight gas-condensate reservoirs: Reduction of Methanol loading and the associated formation damage. J. Nat. Gas Sci. Eng. 2017, 40, 347-355. [CrossRef]

64. Franco, C.; Cardona, L.; Lopera, S.; Mejía, J.; Cortés, F. Heavy oil upgrading and enhanced recovery in a continuous steam injection process assisted by nanoparticulated catalysts. In Proceedings of the SPE Improved Oil Recovery Conference, Tulsa, OK, USA, 11-13 April 2016.

65. Nik, W.W.; Ani, F.; Masjuki, H.; Giap, S.E. Rheology of bio-edible oils according to several rheological models and its potential as hydraulic fluid. Ind. Crop. Prod. 2005, 22, 249-255. [CrossRef]

(C) 2018 by the authors. Licensee MDPI, Basel, Switzerland. This article is an open access article distributed under the terms and conditions of the Creative Commons Attribution (CC BY) license (http:/ / creativecommons.org/licenses/by/4.0/). 